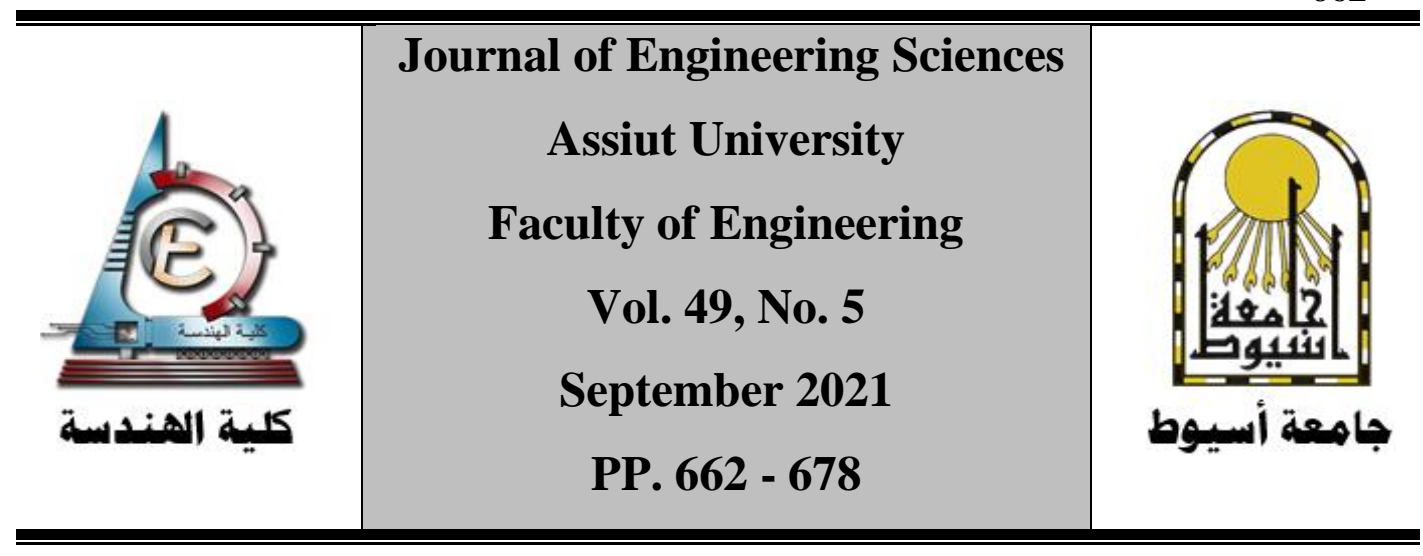

\title{
The Relationship between Urban Spatial Structure \& Commuting Patterns: Literature Review
}

\section{Islam Abouelhamd*1}

\author{
${ }^{1}$ Architectural Engineering Department, Assiut University, 71515, Assiut, Egypt \\ eslam.m.sayed@aun.edu.eg
}

Received 09 January 2021; Revised 29 July 2021; Accepted 2 August 2021

\begin{abstract}
This article is a primary-theoretical research that investigates the effect of urban spatial structure on commuting patterns. The examined variables are the city size, centrality, concentrations of activities, urban densities, and landuses distribution. The selection is based on the most commonly used variables in the literature. The objective is detecting the prior theoretical and empirical contributions from the old and recent studies to conclude the research gap for potential optimization. The prior research confirms that both city size and the distance from the Central Business District are positively led to longer commuting distance, time, and cost. On the contrary, most of the literature has substantiated that the decentralized and densified population, employment, and social services, as well as the mixed land-uses, would notably reduce the average commuting distance, the number of motorized trips, and total vehicles miles travelled. The effect of urban-density and landuses mix remains unclear due to findings that conflict with the empirical results. In the high-densified and diversified districts, traffic congestions may result in longer commuting time, which offsets the decrease in the distance. Furthermore, there is a research gap detected on the effect of the spatial distribution of urban densities, concentrations, and land-uses on the commuting patterns in scale of a city. Finally, this article raises the
\end{abstract}


motivation to empirically investigate these variables in further studies for the Egyptian case.

Keywords: Urban Spatial Structure; Commuting Patterns; Urban Centrality; Urban Densities; Vehicle's miles travelled.

\section{Introduction}

The terms "Urban Spatial Structure" and "Commuting Patterns" are widely founded in different research domains, such as politics, urban economy, history, urban geomorphology, and spatial planning [1]. There is a wide range of definitions in the literature, even in each aspect, there are differences. This section presents different definitions of these terms, which are taken from previous urban studies in the last 30 years, especially the research which concerned about the relationship between urban spatial structure and commuting patterns. Furthermore, it includes clarifications of the differences between commonly used synonyms.

\subsection{Defining Urban Spatial Structure}

Although the term "Urban Spatial Structure" has different definitions in the literature, all of them are associated with a fundamental point, which "Urban spatial structure" as a concept refers to both the functional and morphological characteristics [2]. Generally, it means the discernible patterns in the distribution of human activities within a

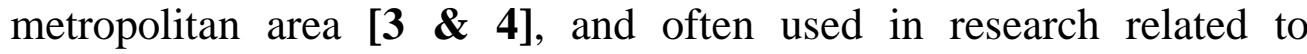
mobility, urban economics, as well as used in some urban sociological and environmental studies.

From the morphological perspective, Boarnet and Wang have defined it as an arrangement of several physical attributes of the urban configurations, including land use mix, city size, density, and spatial clustering which developed by the urban planners, economists, geographers, and other policymakers. It concerns the arrangement of public and private spaces, the degree of connectivity, and accessibility [5]. Muñiz and Sánchez have considered "Urban Spatial Structure" as a combination of population density, job ratio, and distance to the Central Business District (CBD) and sub-centres [6]. Nam also argues in his research that urban spatial structure in the literature and the improved models featured various factors such as size, density, centrality, 
664

concentration, and clustering. Most of the prior research neglected the population and employment densities, although they are highly effective variables in Nam's opinion [7].

From another point of view, Krehl has linked the concept of city models with the term Urban Spatial Patterns. He employed it as an analytical rather than a political-normative notion. He described that city models, whether monocentric, polycentric, or any other models, are directly formed by the distribution of urban centres and land uses within a metropolitan area. Therefore, the city models are the bases to construct the urban spatial structure [3].

Sohn has defined "Urban spatial structure" as "the spatial distribution pattern and densities of urban economic activities and residences along with the existing transport network, which influences urban spatial distribution" [8]. He mentioned that it is essential to understand the "urban spatial patterns" as a key to predict how the transport system would be developed in the city.

The literature has defined "urban spatial structure" by selecting specific physical and nonphysical characteristics. This research concentrates on some of the physical variables including land-uses distribution, centrality, concentration, size of the city, and spatial clustering. As well as some nonphysical variables such as job-housing ratio and urban densities (Population and built-up densities) as a combination of variables that commonly used to determine the urban spatial structure and its effect on commuting patterns. See Figure 1.

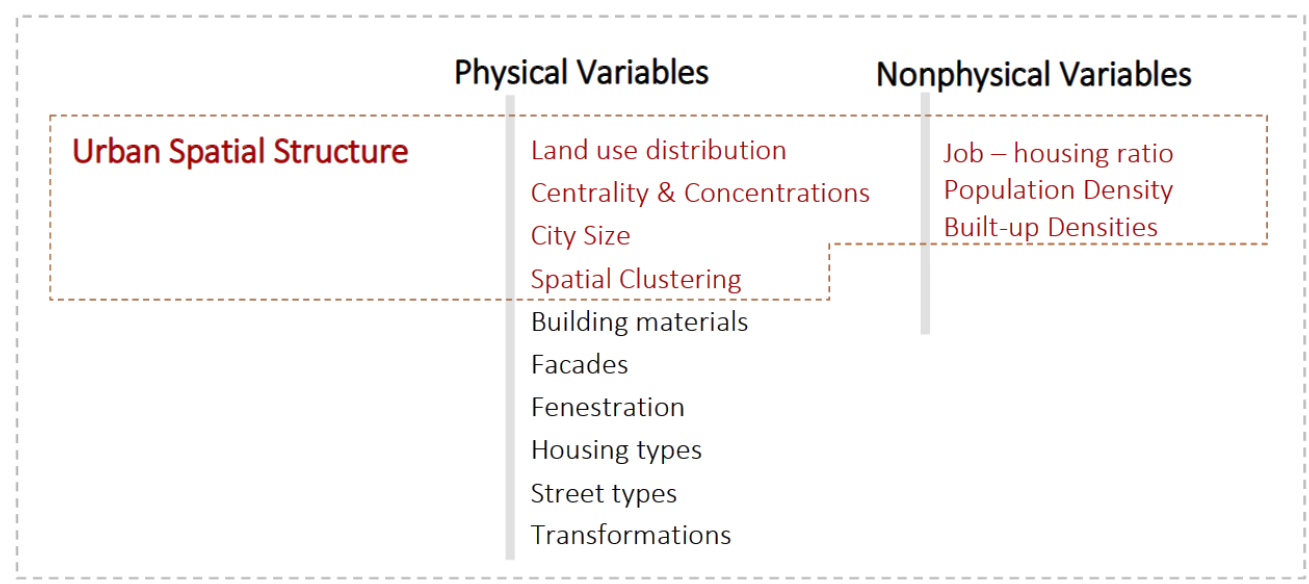

Fig. 1. The physical and nonphysical variables that mainly determine the urban spatial structure and this article have addressed (Author, 2021). 


\subsection{Defining Commuting Patterns}

Commuting is one of the fundamental components of urban transportation. It is a substantial target of urban and transport planners due to its regular patterns [9]. It is a good indicator of traffic congestions, traffic volume, and the prediction of transport-related emissions. It links with the residents' selection of worksites and residence locations. There is common agreement in the literature that commuting and urban spatial structure is strongly correlated urban characteristics $[2,3,9,10$, and 11$]$.

Commuting patterns are periodically recurring travel between the place of residence (Origin) and workplace (Destination), or study, or any regular and often repeated traveling route between two locations, even if not work-related (e.g. commercial or recreational areas) within the metropolitan area. Nevertheless, it should exceed the boundary of one's residential district.

Commuting patterns consist of a combination of attributes, such as the commuting distance, time, and cost (Direct-financial and indirect environmental costs). It can be measured for analysis purposes by different methods, such as the annual total vehicle miles travelled (VMT). Commuting patterns could be distributed in a radically, dispersedly, or randomly forms.

\section{Motivation}

During the last ten years, Egypt witnessed a positive development towards achieving political stability, which accordingly supports the potential urban development and facilitates the fulfillment of the Egyptian vision 2030. The vision states that: "The new Egypt will achieve a competitive, balanced, diversified and knowledge-based economy, characterized by justice, social integration and participation, with a balanced and diversified ecosystem, benefiting from its strategic location and human capital to achieve sustainable development for a better life to all Egyptians" (Egypt Vision 2030, 2015).

One of the fundamental pillars of this vision is to achieve a balanced spatial development, and management of land-uses and resources to accommodate the population growth and improve the quality of life in both the existent and new Egyptian cities. Thus, as a motivation, Egypt needs comprehensive studies that contribute to the improvement of the urban spatial structure and transport system. It requires strategies to 
achieve efficient commuting patterns and eliminate the urban challenges. This research may contribute to that practically in the future.

\section{Objectives}

This research aims to reveal the relationship between urban spatial structure and commuting patterns in the literature. To detect the gab and to initiate practical contributions that targets reducing commuting distance, time, and costs, consequently, to reduce traffic congestions and other indirect impacts on the urban system. It targets the spatial planners, transport developers, and other policymakers to implement policies that fulfill the Egyptian Vision.

\section{Methods \& Data}

To outline the effect of the urban spatial structure on commuting patterns, and to achieve the research objectives, this article follows a literature reviewing methodology with a deductive analysis approach, through conducting a thorough review of the prior empirical and theoretical contributions and to determine the research gap. As well as through deductive Analysis approach, to test the existing concepts and theories which were extracted from the literature review, to find out hypotheses and observations on the topic of the relationship between urban spatial structure and commuting patterns. In particular, this concerns the variables which are missing or have conflict results.

The literature have been selected based on three criteria, first, to be recently published (Most of them published after 2012). Second, it should concern the scale of the city that has between 2 to 5 million inhabitants (Medium scale of the cities which is not over-populated that has complex urban structure and not kind of small cities that does not have traffic-related problems) Third, it should be practical-oriented research that has well-studied methodology.

\section{Urban Spatial Structure Vs. Commuting Patterns}

The relationship between urban spatial structure and commuting patterns has been widely discussed in the literature since the 1980s, a time when megacities with complex urban structure started to emerge. See $[2,4,5,9,10,12,13,14,15,16,17,18,19,20,21,22$, and 23]. It 
is an extensive body and task of research due to the belief that urban spatial structure fundamentally affects commuting patterns which are highly addressed by several urban challenges, such as traffic congestion, motorization, energy consumption, air pollution, and psychological and health issues [11].

The relationship between urban spatial structure and commuting patterns is a vast scientific domain. It has the possibility to break down into many work packages depending on the addressed factors. Thus, each study has its respective specific scope that targets certain factors and scales to achieve specific objectives.

Generally, these factors can be divided into two groups: First, the urban spatial structure factors, such as the size of the city, urban density, urban centrality, concentration, compactness, and diversity of land uses. Second, there are the socioeconomic factors in the scale of the city, such as the history, culture, the institutional structure, economic, and political conditions, as well as in the scale of individuals, including the income, education, age, gender, preferences, and commuting behavior. Figure 2 concludes these groups of factors in a diagram.

From the other side, commuting patterns encompass many sub-aspects, such as the commuting purpose (e.g., to the workplaces, shopping, or recreational areas), commuting frequency, modal choice (e.g., automobile, transit, or walking), commuting distance, time, cost, or accessibility [2].

There are various scales of interest. They range from micro- to macro scales, such as neighborhood, district, city, metropolitan area, or regional scale. However, this research addresses only the urban spatial structure factors in the scale of the city and in some cases the district scale. 
Urban Spatial Structure Factors

City Size \& Distance from the CBD
Urban Densities
Centrality \& Concentrations
Land use mix
Spatial clustering

Socio-economic Factors

City Level

History \& Culture Institutional factors Economic related factors
Individual Level

Income \& Education

Age \& Gender

Preferences \& Attitudes

Commuting Patterns (Distance - Time - Cost - Mode Choice - VMT)

Fig. 2. Diagram demonstrates the factors that have impact on commuting patterns [9 and edited by the author].

\subsection{City Size vs. Commuting Patterns}

The size of the city is an essential variable that indicates the physical extent of the urban structure and commuting patterns. This variable is a fundamental indicator to determine the average commuting distances and time. The previous studies generally agreed that when a city grows physically, average distances to the CBD and other locations increase accordingly. Also, the average commuting time would be augmented. And that leads to an increase in the motorized trips rather than other commuting modes. Nevertheless, this is a simplified approach as it does not consider any other variables $[11, \mathbf{1 5}, \mathbf{1 6}$, and 24]. However, Angel and Blei recently found that this increase is very low in the US cities where commuting times are only $7 \%$ longer in areas twice the size of smaller ones [4].

Several sub-variables influenced by the size of the city and could affect the commuting patterns, such as the size of the CBD and the employment sub-centres. Many studies proved empirically, that there is an inverse relationship between the size of the CBD or the sub-centres and the average commuting distance. That means wider centres or subcentres tend to attract workers by shorter commuting distance and time than the narrow centres [15]. However, it is important to mention that there are no correlations between the size of the city and its average density.

From another perspective, when we consider the demographic size of the city (Population), the number of populations is not an indicator of commuting patterns. Both the number of inhabitants in the place of origins and the number of workers in the destination have a positive effect on the volume of daily commuting flows [18]. Nevertheless, 
although the demographic size is an evident indicator, the population density is a more proper factor to identify this relationship.

After reviewing the literature which concerns the size of the city, there is no research gap observed in this section, and it is even more important and beneficial to focus on other proper variables of urban spatial structure as in the following section.

\subsection{Urban Density vs. Commuting Patterns}

Urban Density is one of the most basic variables associated with the outcome of competition between land use and its associated access patterns [25]. This is the most widely applied characteristic of urban spatial structure in previous empirical studies [16]. This is an important input to the quality of urban life by providing services and access to public and private spaces, including public transport infrastructure [1]. The issue of optimal urban density has been widely debated since the Industrial Revolution. As Betaud stated, the relationship between urban density and commuting patterns plays an important role in determining a city's transportation system and congestion points [26]. Urban density is an abstract term. It consists of several types: human activity (employment, commerce, etc.), buildings, and spatial densification of the population. These are common types that are being studied in the literature to observe their effect on commuting patterns. [See $\mathbf{2 , 1 3 , 1 6 , 1 8 , 2 4 , 2 7}$ and 28].

As an abstract result, a highly concentrated, i.e. densified mix of population, employment, and social services would reduce the average commuting distances, number of motorized trips, and even the total vehicle miles travelled (VMT) [13 \& 27]. Spatially, the residents in the suburbs, where the population and built-up densities are relatively low, tend to travel longer distances using motorized means of transport. In contrast, residents of the high dense neighborhoods tend to commute in shorter distances and to use more sustainable commuting modes such as walking, cycling, and public transportation [2].

Ewing and Cervero have found that population and employment densities are weakly associated with commuting patterns once other variables are examined, such as land use diversity, street network design, and intersection density, which are the strongest variables that can affect the modal choice and walkability [28]. The effect of density remains unclear and inconclusive in the literature, with findings contradicting the empirical results that in the high-density areas, the 
traffic congestions may result in longer commuting time which offsets the decrease in the distance $[11, \mathbf{1 6}, \mathbf{2 0}]$. So, the real impact of densification is ultimately unpredictable and depends on many other characteristics of the city.

The relationship between urban density and commuting patterns has been widely studied and strongly depends on the location and the characteristics of each city. Nonetheless, there is a gap observed in the prior research regarding the study of the impact of urban density distribution on commuting patterns.

\subsection{Centrality \& Concentrations vs. Commuting Patterns}

The spatial distribution of activities in the CBD and sub-centres is a key factor in determining the centrality and concentrations within a metropolitan area [20]. It can influence the commuting flows and interpret how they are distributed, directed, and divided between these centres or sub-centres. In the literature, "centrality" or "centres distribution", also known as a city model in some classical definitions, by classifying the cities to monocentric or polycentric city models. Presently, urban life is taking place in a polycentric city model and even more complex models with random spatial distribution. There are two different perspectives of polycentrism that can be distinguished, the morphological and functional, which are both correlated. While the functional polycentrism takes the functional networks between settlements, the morphological perspective addresses the spatial distribution of urban centers.

The monocentric city model is developed by Alonso, Mills, and Muth in the 1960's and 1970's that use the assumption of the CBD where all the employment and commercial activities lie. The concentration of activities in the central area causes the travel distance to increase linearly with the distance from the CBD. The closest residential area to the CBD has a shorter commuting distance and time. Consequently, the walking and cycling are supposed to be the main commuting mode choices, especially in the limited city size.

The polycentric city model has a decentralized residential, employment, and commercial activities. This phenomenon is known as the "co-location principle" [29]. which supposedly allows employees to find jobs closer to their home. The polycentric transformation comprises a continuing process of employment suburbanization and 
decentralization. Therefore, considerably, both length and duration of commuting are reduced $[8,20,30$, and 31$]$.

Although this result has been substantiated by many studies, there are many empirical contributions provide conflicting results. For instance, the results from U.S. and Europe show that a polycentric city model has a positive relationship with commuting time and distance $[\mathbf{1 0}, \mathbf{1 1}]$. The reason for this is that most workers in the polycentric model do not live close to a center or sub-center where their jobs are located. Consequently, that leads to irregular and random commuting patterns. Moreover, many studies have found that the distance between subcenters and the CBD is negatively associated with commuting time in Atlanta metropolitan area in the USA, which means that dispersed subcenters lead to shorter commutes than the sub-centers closer to the CBD. In contradiction, French and Chinese studies that dispersed subcenters have a lower job/ housing proximity, resulting in longer commutes $[10,11]$. Other results show a weak relationship. Bento and others (2005) have found that more compact employment centrality leads to less individual motorized commute choices and fewer VMT, but in a weak effect. Statistically, a $10 \%$ increase in population centrality lowers the chance that a worker drives to work by only $1 \%$ and reduces VMT by $1.5 \%$.

Access to jobs inside and outside the employment sub-centers are both negatively associated with household VMT. Access to employment in smaller sub-centers has a greater impact on VMT than access to employment in larger sub-centers [5]. For instance, in Seoul, commute times for inner-city sub-centers commuters have significantly reduced. However, new suburban sub-centers (which have attracted more workers from wider job markets) result in longer commute times [11]. Also, emerging employment centers in the outer-ring suburbs of Beijing caused longer commuting distances [10]. Furthermore, Employment centers in the most urbanized areas lead to longer commuting time than non-center areas [10]. Promoting polycentric development in high-density populated city like Beijing may increase the volume of commuting flows. Denser, central, compact, and mixed residential zones make more intense use of transit and non-motorized modes and tend to reduce commuting time [31].

Both the implications of polycentrism and urban density on commuting patterns are not straightforward and have produced divergent results in the literature. Therefore, it is essential to measure both variables in an 
integrated methodology to ensure more accurate outcomes [16]. A study applied by Yao and Kim in US cities using statistical analysis has found that the decentralized high job-density centers could reduce the commuting time of private cars, while it has an insignificant impact on public transit commuting [21]. A study in Beijing has found that promoting polycentric development in these high-density areas may increase the volume of commuting flows, and consequently, more congestion [10].

The impact of polycentrism is more complicated than it seems, and it depends on many other factors to determine its actual effect. Even in the monocentric city model, the density is essential. According to Gordon and others, in monocentric cities, increasing residential density leads to a decrease in commuting time [16 \& 29]. However, the debates on the relationship between polycentrism and commuting patterns are still under review and subject to discussion. Nevertheless, there are more complex city models presented by Betraud [26], such as the constrained dispersal model, the maximum disorder model, and the Mosaic of live-work model, which have not been studied yet in the literature.

\subsection{Land-Uses \& Spatial Clustering vs. Commuting Patterns}

Since the first conceptual schemas of urban structure theories presented by Ernest Burgess in 1920's, the relationship between land uses and commuting patterns has been widely studied and discussed worldwide until recent days. The first classical models in the 20th century have proposed a primary vision of land-uses allocation in the city. Three main models have been generated, the concentric theory of urban structure, the sectorial theory, and the multiple nuclei theory. Recently, many debates have developed to discuss this relationship extensively by several analysis approaches. Two main aspects have studied to examine the relationship between land-uses and commuting patterns, the spatial distribution of employment centers, and housing, which commonly known as Job-housing balance, as well as the degree of land use diversity, mix, or clustering.

Land-uses and commuting patterns are highly correlated. While home to work commuting patterns strongly reflect the activity nodes and land-use configuration [2], land use types of origins and destinations have an impact on the volume of commuting patterns [18]. Many studies confirm that land-use factors are notably affecting the 
commuting flows and sustainability of transport systems in urban areas, as well as it is a key factor of transport efficiency.

Previous debates have reported that the spatial balance between the jobs and houses is strongly affecting commuting patterns. Lin and others have found that the job-housing balance in polycentric urban development would reduce the duration of commuting patterns [9]. They suggested methods to achieve the balance, either by following the co-location of jobs and houses driven by market forces or by allocation of the housing supply via urban planning policy and government intervention [9]. Furthermore, Duarte and Fernández have found that commuting is exacerbated in areas where employment dominates over housing, especially if jobs are oriented to manufacturing [15]. For instance, Liu has confirmed in his study that Industrial sub-districts are significantly attracting commuters from commercial, educational landuses and residential sub-districts, which could increase the commuting flow and congestions [20]. Furthermore, residence and work-location type can influence commuting mode choices [2]. A study reported that Job-housing balance is not as effective way in developing counties as in the case of developed countries due to lack of transport infrastructure and constraints on spatial planning [24].

The degree of land-uses mix (At the scale of the city) is one of the complicated factors associated with commuting patterns. There are many conflicting results. Some studies confirmed that mixed land-use development, by concentrating residence, employment, and social services in the inner part of the city and around the sub-centres, is a substantial driver of commuting efficiency [11]. It reduces the average commuting distance and number of motorized vehicles [13]. Ewing and Cervero have found that neighborhoods with diversified land-uses have better accessibility, and therefore it is the most effective variable to encourage walkability in the city [28]. Some other studies proved that the effect of mixing land-uses is low. Therefore, improving the landuse mix will only have a limited tangible impact on commuting distance. However, the segregated land-uses, or as it known by the notion "spatial clustering" (the opposite of land-uses mix) may be more beneficial for limiting commuting patterns. It facilitates the development of efficient transport infrastructure, especially clusters with high jobs and housing densities [16]. 


\section{Conclusions}

This research aims to examine the effect of some characteristics of urban spatial structure on commuting patterns based on literature review and deductive analysis of the existing theories and findings. Despite the enormous amount of literature concerned about the relationship between urban spatial structure and commuting patterns, several reasons have been reported to detect the insufficient and inconclusive prior results. First, there are highly conflicting findings on the impact of urban density, land-uses distribution, and spatial clustering on commuting patterns. There is a gap in examining the implications of the spatial distribution of urban densities from the CBD to the periphery. Moreover, most of the previous studies have been oriented to study the job-house commuting patterns without considering other means of daily trips, such as to the commercial and recreational areas.

The literature confirms that the size of the city and the distance from the CBD positively lead to longer commuting distance, cost, and time. There is an inverse relationship between the size of the CBD or the sub-centres and the average commuting distance. That means wider centres or sub-centres tend to attract workers by shorter commuting distance and time than the narrow centres.

The relevant literature has substantiated that the decentralized and high density of population, employment, and social services, as well as the mixed land-uses districts, would notably reduce the average commuting distance, the number of motorized trips, and total vehicles miles traveled (VTM). Spatially, the residents in the suburbs, where the population and built-up densities are relatively low, tend to travel longer distances using motorized means of transport. In contrast, residents of the high dense neighborhoods tend to commute in shorter distances and to use more sustainable commuting modes such as walking, cycling, and public transit. Nevertheless, the effect of urban density and land-uses mix remains unclear and inconclusive given the conflicting empirical findings that in the highly densified and diversified districts, the traffic congestions may result in longer commuting time, which offsets the decrease in the distance.

Nonetheless, little attention has been placed on the effect of the spatial distribution of urban densities and land-uses on the commuting patterns. Although the impact of polycentrism introduced and examined widely, but there is a lack of examining the effect of the 
complicated forms of polycentrism, such as the constrained dispersal model, the maximum disorder model, and the Mosaic of live-work communities' model.

From another perspective, few studies in the literature addressed the mega-cities or the over-populated agglomerations (more than 10 million inhabitants) as a case-study. The characteristics of these cities are incomparable to the other medium-sized cities. The degree of urban-density is much higher. The urban expansion and population growth is five to eight times greater. Therefore, the results of this research are partly inapplicable for such a complex urban systems where complex physical and socio-economic variables should be addressed perfectly. Eventually, this article pushes up a motivation to examine these variables empirically in further research with considering a case-study.

\section{References}

[1] Paramita, B. (2011) Shaping Urban Spatial Structure [Online], Conference: SGRA. Available at: https://www.researchgate.net/publication/233726166_Shaping_Urban_Spatial_ Structure.

[2] Acheampong, R. A. (2020) 'Spatial structure, intra-urban commuting patterns and travel mode choice: Analyses of relationships in the Kumasi Metropolis, Ghana', Cities, vol. 96, p. 102432.

[3] Krehl, A. (2015) 'Urban spatial structure: An interaction between employment and built-up volumes', Regional Studies, Regional Science, vol. 2, no. 1, pp. 290-308.

[4] Angel, S. and Blei, A. M. (2016) 'The spatial structure of American cities: The great majority of workplaces are no longer in CBDs, employment sub-centers, or live-work communities', Cities, vol. 51, pp. 21-35.

[5] Boarnet, M. G. and Wang, X. (2019) 'Urban spatial structure and the potential for vehicle miles traveled reduction: The effects of accessibility to jobs within and beyond employment sub-centers', The Annals of Regional Science, vol. 122, p. 775.

[6] Muñiz, I. and Sánchez, V. (2018) 'Urban Spatial Form and Structure and Greenhouse-gas Emissions from Commuting in the Metropolitan Zone of Mexico Valley', Ecological Economics, vol. 147, pp. 353-364.

[7] Nam, K., Kim, B. and Lim, U. (2016) 'Quantitative Regional Economic and Environmental Analysis for Sustainability in Korea', Quantitative Regional Economic and Environmental Analysis for Sustainability in Korea, pp. 171189 [Online]. Available at DOI 10.1007/978-981-10-0300-4_10.

[8] Sohn, J. (2005) 'Are commuting patterns a good indicator of urban spatial structure?', Journal of Transport Geography, vol. 13, no. 4, pp. 306-317. 
[9] Lin, D., Allana, A. and Cui, J. (2015) 'The impacts of urban spatial structure and socio-economic factors on patterns of commuting: a review', International Journal of Urban Sciences, Pages 238-255 [Online]. Available at http://dx.doi.org/10.1080/12265934.2015.1016092.

[10] Hu, L., Sun, T. and Wang, L. (2018) 'Evolving urban spatial structure and commuting patterns: A case study of Beijing, China', Transportation Research Part D: Transport and Environment, vol. 59, pp. 11-22.

[11] Jun, M.-J. (2020) 'The effects of polycentric evolution on commute times in a polycentric compact city: A case of the Seoul Metropolitan Area', Cities, vol. 98, p. 102587.

[12] Antipova, A. (2018) Urban environment, travel behavior, health, and resident satisfaction, Cham, Palgrave Macmillan.

[13] Cervero, R. (1989) 'Jobs-Housing Balancing and Regional Mobility', Journal of the American Planning Association, vol. 55, no. 2, pp. 136-150.

[14] Dong, T., Jiao, L., Xu, G., Yang, L. and Liu, J. (2019) 'Towards sustainability: Analyzing changing urban form patterns in the United States, Europe, and China', Science of The Total Environment, vol. 671, pp. 632-643.

[15] Duarte, C. M. and Fernández, M. T. (2017) 'The Influence of Urban Structure on Commuting: An Analysis for the Main Metropolitan Systems in Spain', Procedia Engineering, vol. 198, pp. 52-68.

[16] Engelfriet, L. and Koomen, E. (2018) 'The impact of urban form on commuting in large Chinese cities', Transportation, vol. 45, no. 5, pp. 1269-1295.

[17] Fosgerau, M. and Kim, J. (2019) 'Commuting and land use in a city with bottlenecks: Theory and evidence', Regional Science and Urban Economics, vol. 77, pp. 182-204.

[18] Liu, Y., Fang, F. and Jing, Y. (2020) 'How urban land use influences commuting flows in Wuhan, Central China: A mobile phone signaling data perspective', Sustainable Cities and Society, vol. 53, p. 101914.

[19] Lu, Y., Sun, G., Sarkar, C., Gou, Z. and Xiao, Y. (2018) 'Commuting Mode Choice in a High-Density City: Do Land-Use Density and Diversity Matter in Hong Kong?', International Journal of Environmental Research and Public Health, vol. 15 , no. 5, p. 920.

[20] Marcińczak, S. and Bartosiewicz, B. (2018) 'Commuting patterns and urban form: Evidence from Poland', Journal of Transport Geography, vol. 70, pp. 3139.

[21] Yao, Z. and Kim, C. (2017) 'The Changes of Urban Structure and Commuting: An Application to Metropolitan Statistical Areas in the United States', International Regional Science Review, vol. 42, no. 1, pp. 3-30.

[22] Zhang, Z. (2017) 'A Study on Urban Spatial Structure in the Context of the Jobs-Housing Balance: A Case of Suzhou, China', Smart Growth and Sustainable Development, GeoJournal Library 122, pp. 73-85.

[23] Zhou, H. and Gao, H. (2020) 'The impact of urban morphology on urban transportation mode: A case study of Tokyo', Case Studies on Transport Policy, vol. 8, no. 1, pp. 197-205.

[24] Sun, B., Zhang, T., He, Z. and Wang, R. (2016) 'URBAN SPATIAL STRUCTURE AND MOTORIZATION IN CHINA', Journal of Regional Science, vol. 57, no. 3, pp. 470-486. 
[25] Krehl, A., Siedentop, S., Taubenböck, H. and Wurm, M. (2016) 'A Comprehensive View on Urban Spatial Structure: Urban Density Patterns of German City Regions', ISPRS International Journal of Geo-Information, vol. 5, no. 6, p. 76 .

[26] Bertaud, A. (2004) The Spatial Organization of Cities: Deliberate Outcome or Unforeseen Consequence?: Working Paper [Online], 01th edn, University of California, Institute of Urban and Regional Development, Berkeley, CA.

[27] Chatman, D. G. (2003) 'How Density and Mixed Uses at the Workplace Affect Personal Commercial Travel and Commute Mode Choice', Transportation Research Record: Journal of the Transportation Research Board, vol. 1831, no. 1, pp. 193-201.

[28] Ewing, R. and Cervero, R. (2010) 'Travel and the Built Environment', Journal of the American Planning Association, vol. 76, no. 3, pp. 265-294.

[29] Gordon, P. and Richardson, H. W. (1996) 'Beyond Polycentricity: The Dispersed Metropolis, Los Angeles, 1970-1990', Journal of the American Planning Association, vol. 62, no. 3, pp. 289-295.

[30] Bento, A. M., Cropper, M. L., Mobarak, A. M. and Vinha, K. (2005) 'The Effects of Urban Spatial Structure on Travel Demand in the United States', Review of Economics and Statistics, vol. 87, no. 3, pp. 466-478.

[31] Silva, J. d. A. e., Golob, T. F. and Goulias, K. G. (2006) 'Effects of Land Use Characteristics on Residence and Employment Location and Travel Behavior of Urban Adult Workers', Smart Growth and Sustainable Development, GeoJournal Library 122, vol. 1977, no. 1, pp. 121- 131. 


\section{دراسة العلاقة بين البنية المكانية الحضرية وأنماط التنقل: مراجعة للأدبيات}

الملخص

هذه المقالة عبارة عن بحث إبتدائي نظري يبحث في تأثير البنية المكانية الحضرية

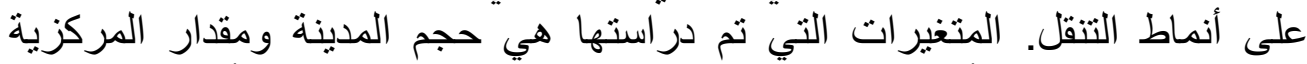

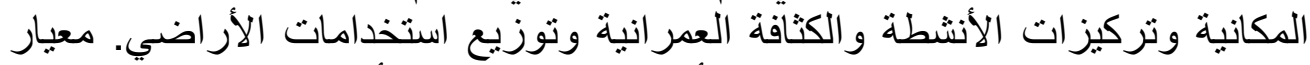

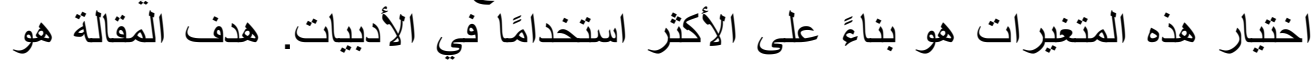

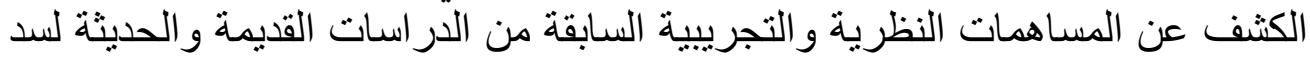

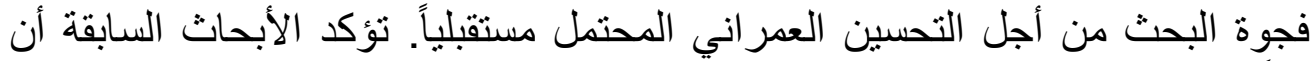
كلاً من المتغيرين حجم المدينة والمسافة من مركز المدينة الحيوي يؤديان بثنكل

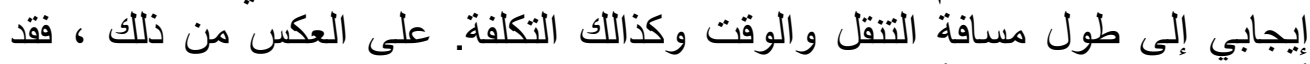
أثبتت معظم المؤلفات أن المدن المتعددة المراكز الحيوية وعالية الكثافة السكانية،

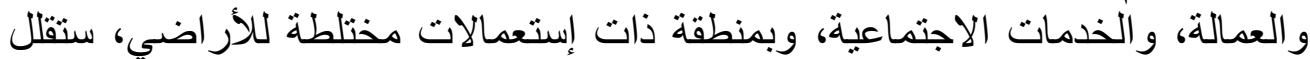

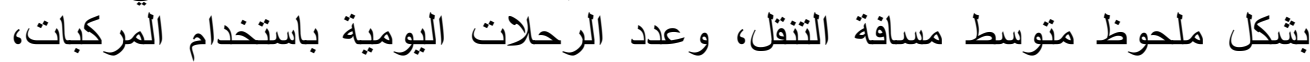
و إجمالي مسافة الرحلات للمركبات. في حين أنه لا يزال تأثير الكثافة العدرانية و استخدامات الأراضي غير واضيح بسبب النتائج التي تتعارض ضين مع النتائج التجريبية.

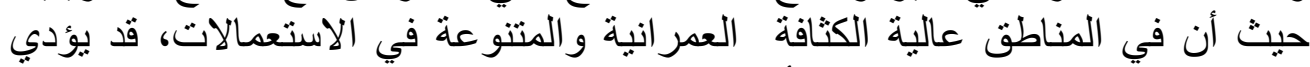

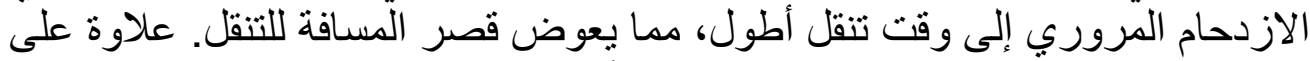

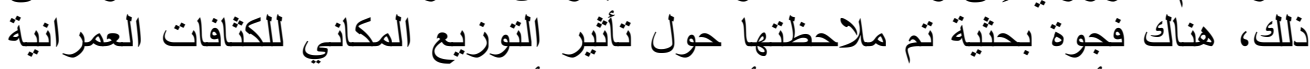
وتركيزات الأنشطة واستخدامات الأراضي على أنماط التنقل في نطاق المدينة. في النهاية، تثير هذه المقالة الدافع للدراسة التجريبية لهذه المتغيرات في مزيد من الدراسات المستقبلية لحالة المدن المصرية. 